\title{
A Teaching Experiment between Design Concept and Structural Behaviour: Full-Scale Constructions in a Second-Year Studio
}

\author{
Fausto Novi and Chiara Piccardo \\ Department of Sciences for Architecture, University of Genoa, Genoa 16123, Italy
}

\begin{abstract}
Consciousness is the main quality one can ask architecture students. Consciousness means the ability to recognize that the design process is a "problem solving" activity and not an exercise of uncontrolled imagination. In architectural education, small structures are a common subject in American and European universities where the inductive teaching is practiced routinely. This teaching experiment is developed within a design studio course in the second year of an architecture degree course and regards design and construction of a small bridge 1:1 scale. The exercises focus on the role of structural behaviour within architectural design. The teaching method contributes to the perception of the great complexity of the design process, to the acquisition of an attitude of prudence in design choices and to attention to detail in the development of creativity.
\end{abstract}

Key words: Design education, design process, design technology, teaching experiment.

\section{Introduction}

The design studio course where the teaching experiment was conducted aims to highlight the role of technology and technique in architectural design, considered as elements for inspiration and growth within the design process and not as "unpleasant" constraints or limitations of the artistic designer's freedom.

Therefore, technology and technique could not be imposed retrospectively on design ideas abstractly conceived or even that a chronological order may exist between the origin of the design idea and its materialization during the development and refining stages of the project. The design idea, from the early stages of evolution, must contain the potential for its development and construction, although brief and superficial, and must also suggest its own material aspect. This statement, although in recent decades is shared by much of the international literature on the architectural education, is still in open conflict with

Corresponding author: Fausto Novi, professor, research field: architectural technology. the traditional method of design education applied in many architecture schools [1].

There are two main critical elements in contemporary architectural education. On the one hand, especially in the early years of degree courses, there is an excess of theoretical information that are not absorbed enough by the students, since too distant from application [2]. Therefore, the deductive method dominates in the education programs, at the expense of inductive approaches (almost totally absent) and this is likely to further alienate theory from practice.

On the other hand, there is a lack of integration of knowledge and disciplines, which are taught in "separate worlds", that never find a cognitive synthesis in the projects discussed during the degree course. In particular, there is a growing difficulty in the schools of architecture to integrate the compartmentalized scientific and technical training in the design project. Often, architecture is primarily considered as an image, rarely is possible to see details and very seldom the "reasons why" behind a project are told. The process that determines the 
architecture (and its image) is always mysterious.

These considerations can be connected to the general tendency of the media to communicate contemporary architecture, where the image "undeniably fascinating" prevails on tectonics, that is to say a complex of issues and concerns of structure, technology, construction, etc.

Similarly, the image of architecture that emerges appears to be only the result of the designer's will and never seems to have been descending from specific situations that have led (or forced) to make some choices or to accept some compromises [3].

The link between technical research and formal research is increasingly thin and fragile, and often results in the search for a "surprise effect", in the escalation for the most innovative coating or the most attractive "packaging" (not necessarily aware of its content). For these "Photoshop" architectures, whose skin is a veil stretched on a dark and mysterious structure, where little is understood and even less is constructible, it will be necessary the acrobatics of plant engineers and structural engineers (their fees included in the final cost of the work).

Students of architecture, mainly in their early stages of training, are asked to be conscious. The design process is a "problem solving" activity and not an exercise of uncontrolled imagination. Creativity in architecture (as in all human activities) must be related to the practical feasibility of what is imagined [4].

The architect, in this meaning, cannot be simply defined as a producer of images, a particularly risky position, however, because open to the judgment of the subjectivity of others, subject to claims of perceptive, social, economic nature, etc., but also must be also able to translate these images into a concrete space proposal.

In addition, the consciousness of the role of science and technology and of what they can offer in architectural design helps the architect to control the amount of information available, without being overwhelmed. The amount of materials and technologies continually proposed by the market, in fact, is no longer manageable by the designer, if not through a global awareness of the project. In this regard, access to the network, which is the main means of information for students, may be confusing or redundant by the number and variety of data.

The acquisition of consciousness of the design process by students is an ambitious goal that can be achieved in the design studios-even in the short time granted by the university-through the formulation of simple themes, whose complete exploration is possible, often turning to experimentations based on "learning by doing", rather than through arbitrarily simplified complex issues, where the design choices are difficult, not supported by adequate knowledge, often fortuitous, or adapted to the "style" of the teacher [5].

The themes developed by the studios are organized as a sequence of several short exercises, whose objectives are progressively more complex: They start from the design of simple objects, made with a material assigned or chosen by the students, highlighting the relationships among materials, shape, connections and details (including the "bridge for rabbit", described below), to the last exercise that involves a small architectural space.

The first design exercise is about the relationships among materials, shape, connections and details. The goal is to discover the possibilities offered by a particular material, just one, to fulfill a specific object, both assigned by the teachers. Students must design and build their own ideas, building a prototype in 1:1 or 1:2 scale, understanding and taking full advantage of a particular resource (a single material and its related technology) and applying creativity in an apparently very narrow environment (the assigned object, in a suitable size to be easily handled, completely free of functionality).

The second design exercise aims to show how a material or a technology can influence, even in a 
decisive manner, the appearance of a given object. The only constraints imposed are the topic of this exercise, along with some dimensional data, deliberately severe and sometimes even absurd. The object can be designed and built with any material or technique chosen by students. In this case, the exercise is similar to a real challenge, with its limitations and constraints, where it is possible to recognize, on the one hand, the ideas that originate from one technique or material and are choosing their form and, secondly, the ideas originate from a form that are choosing the appropriate technological solution.

The third exercise (described below in detail) is intended to examine and test the role of the structural behaviour, especially with respect to the concept of stability, within the architectural design, highlighting the mutual influence between structural need of an idea and formal ambition of the designer. The exercise proposed calls for the realization of what has been designed in 1:1 scale, with particular attention to the joints and to the way the loads are transferred through them, and for the verification of the general physical behaviour of the construction. The exercise takes place also with the complicity of structures teachers.

The fourth exercise adds to the elements progressively addressed previously, even the architectural space, and is a small building that offers simple performances. This exercise requires a complete project, related with a climatic context of reference and sometimes with a specific place. This is the most complex project and of longer duration among those assigned during the studio course.

Most exercises developed in the studio include the manufacture of what is planned. This is not a common custom in our educational system, where manual construction is usually little used and viewed with suspicion, because of the extravagant and artistic aspects and the scientific-technical approximation of what is realized. However, the manufacture obliges students to turn ideas into functioning objects and, in particular, to use drawings as means not only of representation but investigation [6].

\section{The Teaching Experiment: A Bridge for Rabbits}

The teaching experiment is intended to examine and test the role of the structural behaviour, especially with respect to the concept of stability, within architectural design. The title of the exercise is clearly an amusing expedient to engage students, who are called to pursue the following objectives:

- recognize the role of structure in the architecture project and discuss the extent to which it is at the service of the architectural image and/or the extent to which it is a logic and physical construction tool, according to the limits imposed on the technical feasibility of construction;

- become aware of the link between design concept and structural-static behaviour, without the need for calculations (the students have, usually, only some of the theoretical knowledge to deal with these), but rather through the qualitative understanding of the structural working principle integrated in the overall project idea.

From the educational point of view, this exercise is an attempt to establish an understandable clear relationship between the design and structural disciplines.

For this purpose, over the years, various design exercises have been submitted, all referring to architectural subjects with strong evidence of the formal role of structure and, at the same time, not over-demanding in terms of performance and easy to verify and test with simple tools. Small bridges, vertical structures and various supports, stools, etc., have been proposed. However, the bridge is definitely the most exciting for the students and has much more literature and studies carried out in European and American universities [7].

Although, in some cases, these exercises were based mainly on intuition and constructive luck, rather 
than on the attempt to apply technical and scientific knowledge, and although the use of materials completely without any structural performance (for example, spaghetti, drinking straws, ice cream sticks, paper, etc.) came close to making it an ability game, the aspect of the game, the challenge implicit in the use of odd materials, as well as the search for solutions to overcome the inefficiency of the assigned materials, are certainly interesting from an educational point of view (Figs. 1-3) [8].

Another interesting aspect is the demand to design and build an object at 1:1 scale-even if small-that leads students to compete with real structural behaviour. It is not, therefore, a scale model of a larger object, a "mock-up", but a real object, for which students measure themselves with the structural behaviour (dependent on the static scheme and the material chosen), with the construction aspects and with the difficulties depending on the quality of the assembly and manufacture of the joints (both carried out, of course, by the students).

This exercise is organized in three times: design, construction and final testing of a bridge, having maximum clear span $(70 \mathrm{~cm})$ and width dimensions $(10 \mathrm{~cm})$ assigned, using prescribed materials (quality and quantity) provided by the teachers. The bridge must support a load of $5 \mathrm{~kg}$, equivalent to the weight of the rabbit.

The choice of bamboo skewers, as the material to be used for the design and the construction, meets a series of requirements: be readily available and inexpensive, workable even in the classroom with easy to use and non-hazardous tools, being a not brittle material, with good mechanical properties and a fibrous structure.

Regarding the exercise, the material is not easy to use for several reasons: (1) The length of the single "rod" is much less than the span of the bridge (this implies the use of more rods, connected together, to overcome the distance); (2) The single rod is unstable in compression and has an elastic behaviour. For this
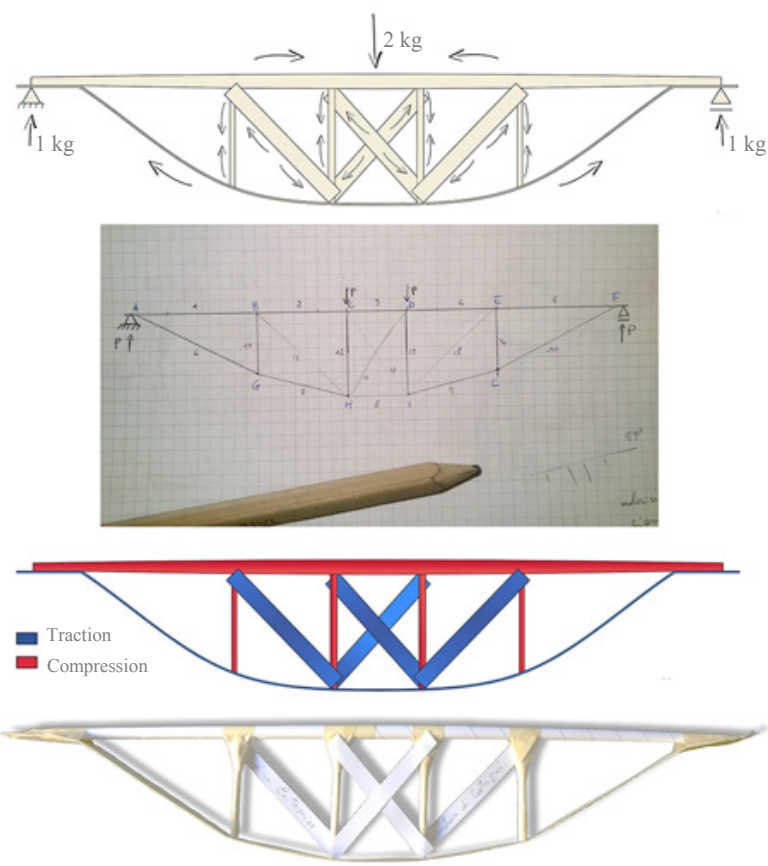

Fig. 1 Paper beams.

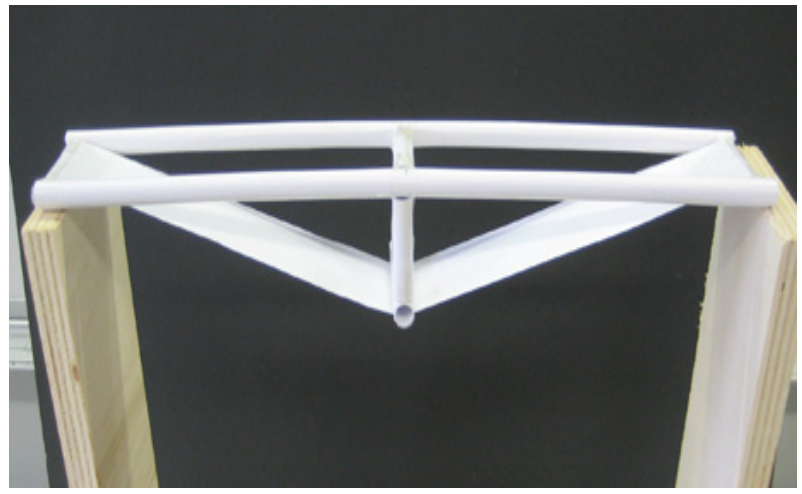

Fig. 2 Paper beams.

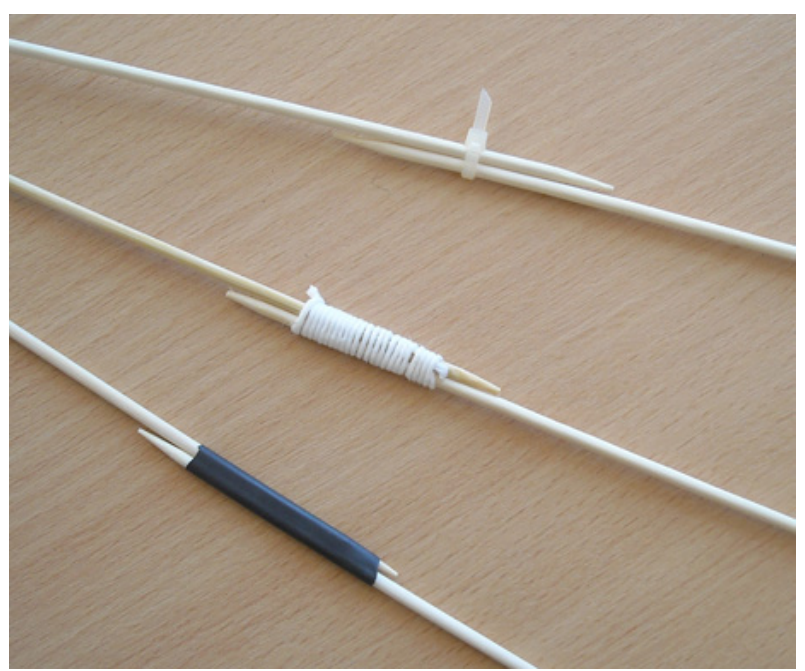

Fig. 3 Bamboo skewers connections. 
reason, great care in design and construction is required to avoid instability; (3) Evidently, it is a material that is deliberately far from a constructive use and "unfit" for the purpose, in order to stimulate students in an inductive environment.

During the test, the bridges, previously weighed and numbered, are progressively loaded with steel ingots (increments of $500 \mathrm{~g}$ ), up to collapse (rupture, remarkable deformation and loss of stability). Once reached a load of $5 \mathrm{~kg}$ without failure, the test will continue until failure, but the nominal resistance will be considered the one corresponding to the $5-\mathrm{kg}$ weight.

Finally, it is not evaluated as the most "resistant" structure (the load supported until failure), but the most "efficient" construction given the assigned design load (its own weight compared to the load assigned limit). The over-performing, and probably heavier, bridges are therefore downgraded in terms of efficiency.

During the various exercises, it was observed that the introduction of the efficiency requirement, in addition to that of resistance, has greatly stimulated the students to make a greater design effort, either regarding the use of the material, entrusting the resistance of the bridge to a reasonable number of rods, or with respect to the configuration of the joints, with benefit in most cases, however, for the architectural image.

\section{Design Issues}

Since the first phase of the design process, students fight with the need to manage their formal ambitions along with the structural instances. Evidently, there are no references in the literature to similar constructions. This encourages students to search for "ad hoc" solutions, experiencing the operational mode of structural schemes and structural joints using prototypes.

Although students are required to meet a number of functional and dimensional constraints, as already mentioned, the design starting phase normally creates some discomfort. Among the reasons for this feeling, there is certainly the singularity of the assigned exercise, the unusual material to be used and the impossibility of dealing with projects already developed and implemented.

Since from this first phase of the design process, students clash with the need to manage their formal ambitions along with the structural instances, trying to understand the role of the structure within their project.

In the development of the project idea, students follow their own different strategies: the reference to already viewed architectures or to other sources (common objects, etc.), or to structural patterns, the manipulation of the material assigned for the construction and the test of possible methods for making connections, etc.

The phase of conception of the idea is, therefore, usually accompanied by a phase of investigation, required to inform the project with the properties of the materials, the technological choices and the structural patterns.

The developed projects can be divided into different categories, characterized by different structural concepts (arches, reinforced beams, trusses, and mixed solutions). The first category, generically called "arches", is certainly one of the largest in terms of projects developed. Even in the category of reinforced beams different structural patterns have been used, with a prevalence of lattice space systems, where attention to the jointing system has proved to be critical for the structural behaviour and the aesthetics, given the large number of converging rods to be connected. The category represented by the truss structures has proven to be less efficient in terms of the ratio carried load/weight. This is due to the greater number of rods made necessary for the structural system chosen. A small number of other projects, called "mixed solutions", have developed alternative structural patterns, between arch and reinforced beam or between arch and truss, exploring with great risks 

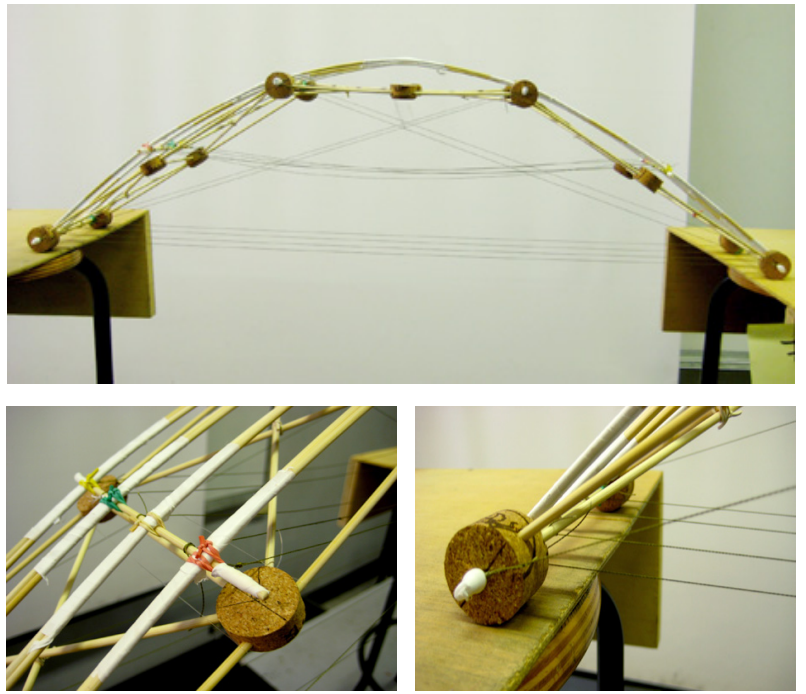

Fig. 4 Arch-type bridge and details.
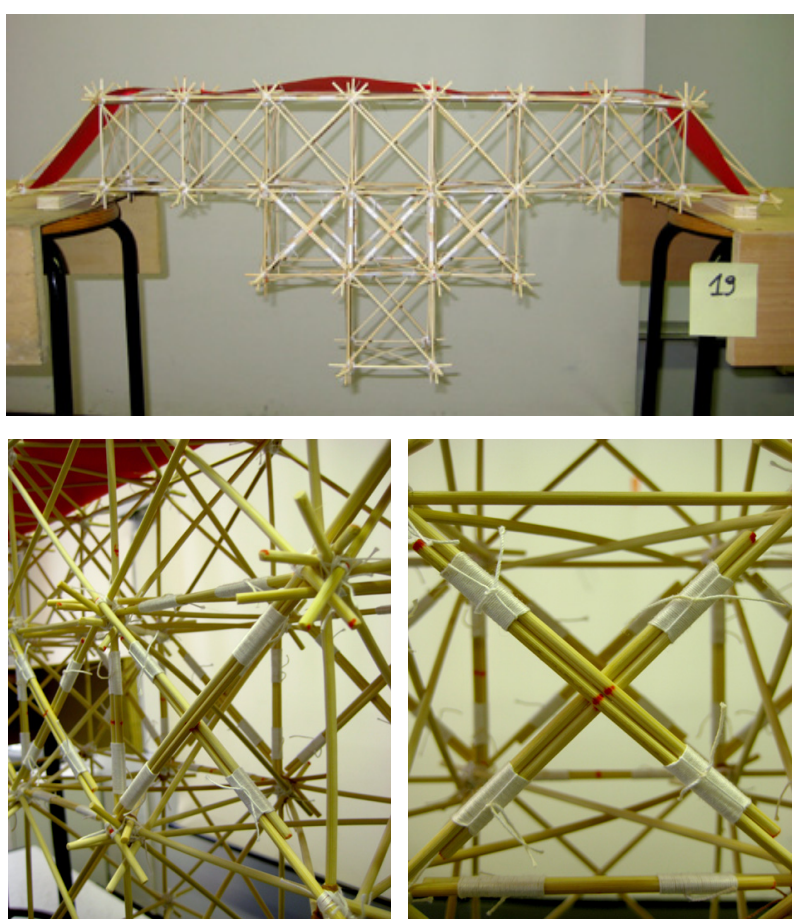

Fig. 5 Truss-type bridge and details.

the limits of instability (Figs. 4-8).

Different materials have been used for the construction of the connections (string, Teflon, etc., to more complex systems, e.g., wire and medical thin pipes). Mechanical systems and adhesives are strictly excluded. The choice of such materials, in addition to the number of joints provided, was critical for the weight of the bridge and, thus, to the achievement of satisfactory efficiency values.
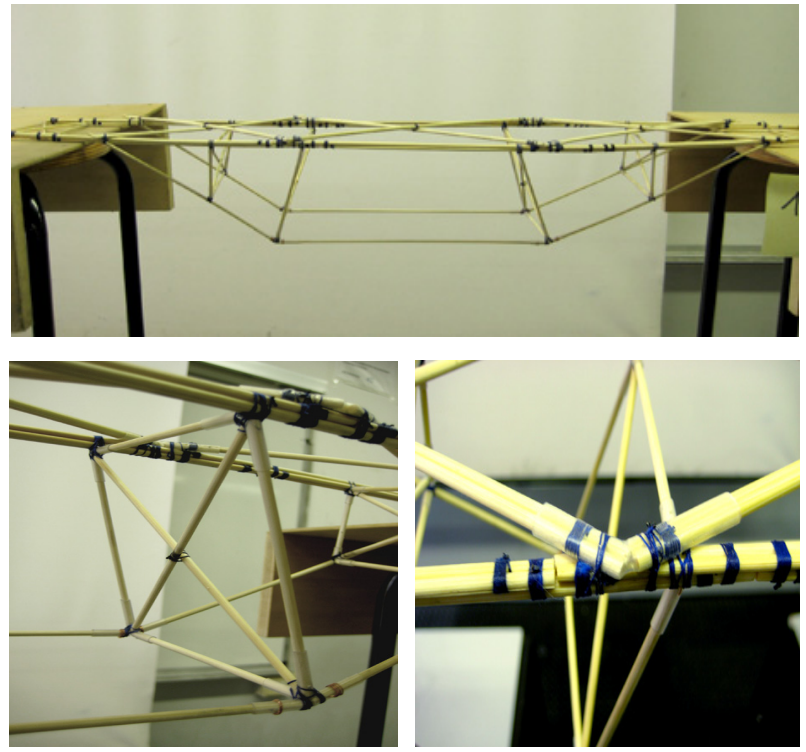

Fig. 6 Reinforced beam-type bridge and details.
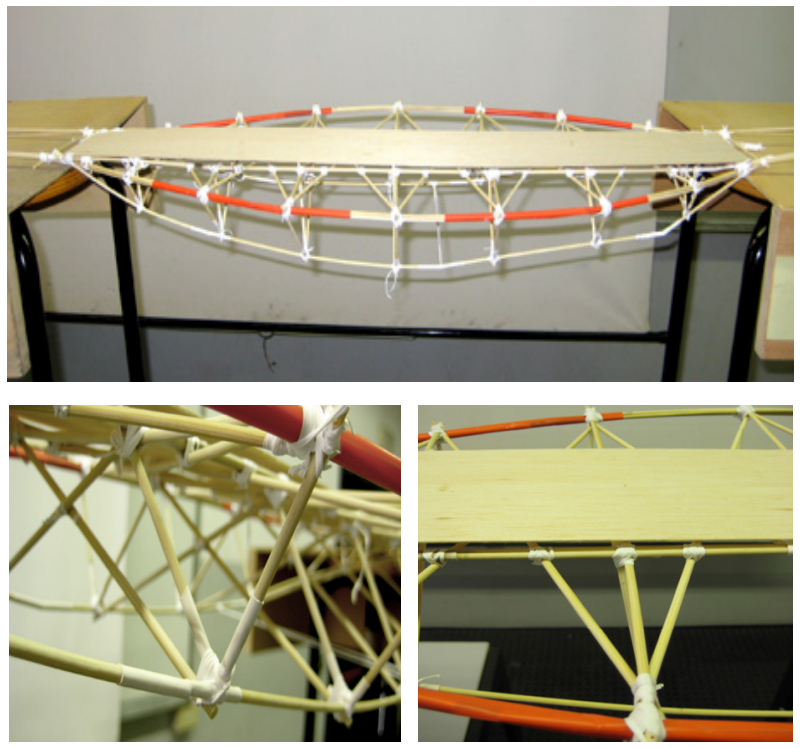

Fig. 7 Reinforced beam-type bridge and details.
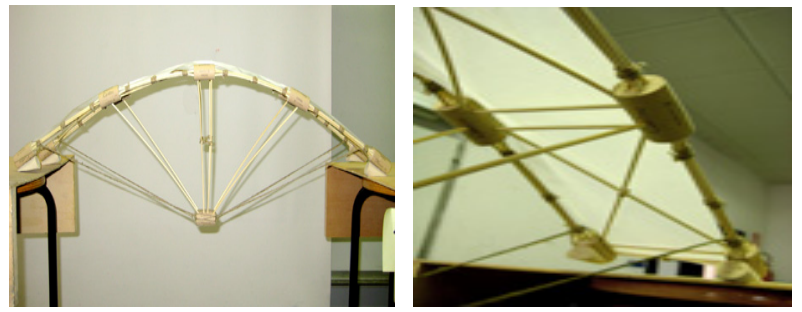

Fig. 8 Arch-type bridge and details.

The results of the final tests have been extremely encouraging, with a carried load/bridge weight ratio up to a maximum of 130 times and a minimum construction weight of $130 \mathrm{~g}$. 
When near to load supporting limit, the bridges tend to break at the most stressed rods or in corresponding rods where an abnormal load distribution (due to structural design or construction faults) may cause unpredictable breakages.

The most frequent cause of bridge failure is linked to the instability of the rods, which sometimes is not adequately resolved by structural design; Also, however, the faults of construction and joints manufacture may be decisive in a premature breakage or instability of the bridge (Figs. 9-12).

Anyway the design, development and construction of a tangible "thing" allow students to understand, at least within the limits of the brief experience accomplished, how much complex and rich (and pleasant and fun) could be a design experience. This also allows students to evaluate their own work, to drive and adapt the project to the constraints imposed, without fear and without censorship, and to be able to measure the distance between the expected and the real, between the mind and the hand.

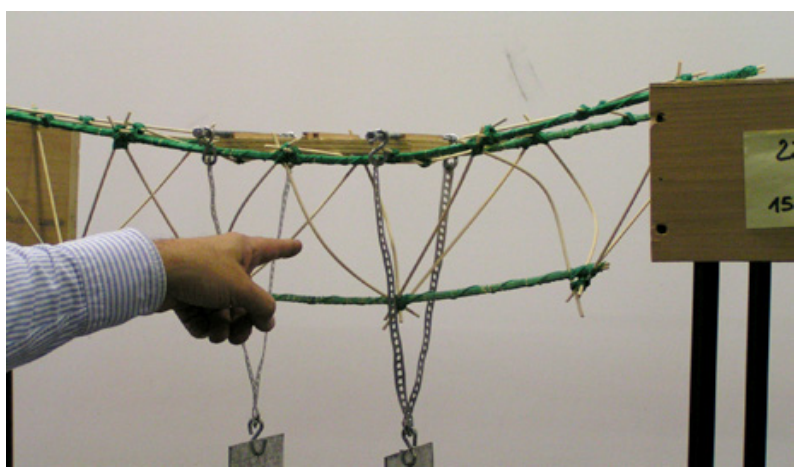

Fig. 9 Bridges testing in the classroom.

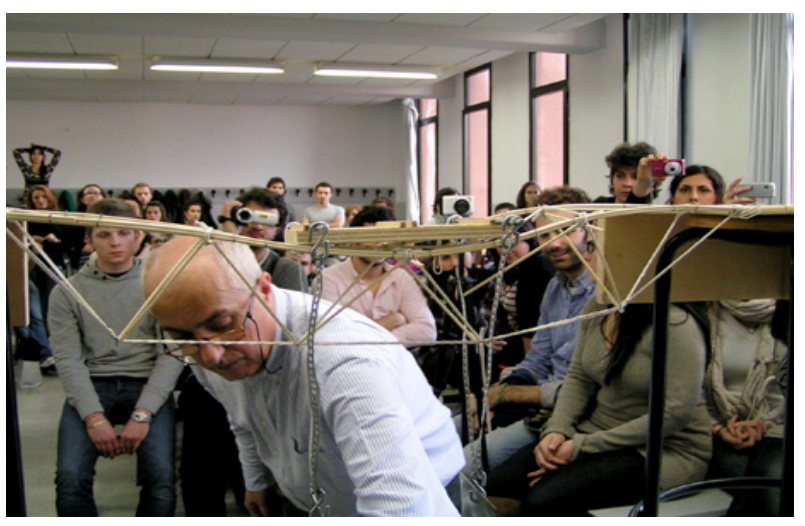

Fig. 10 Bridges testing in the classroom.

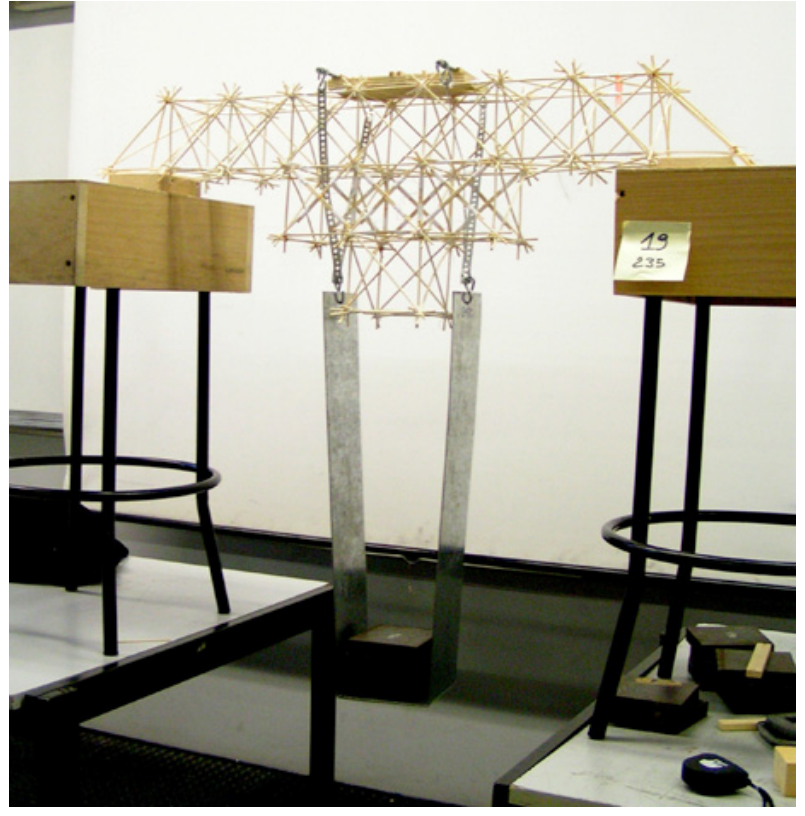

Fig. 11 Bridges testing in the classroom.

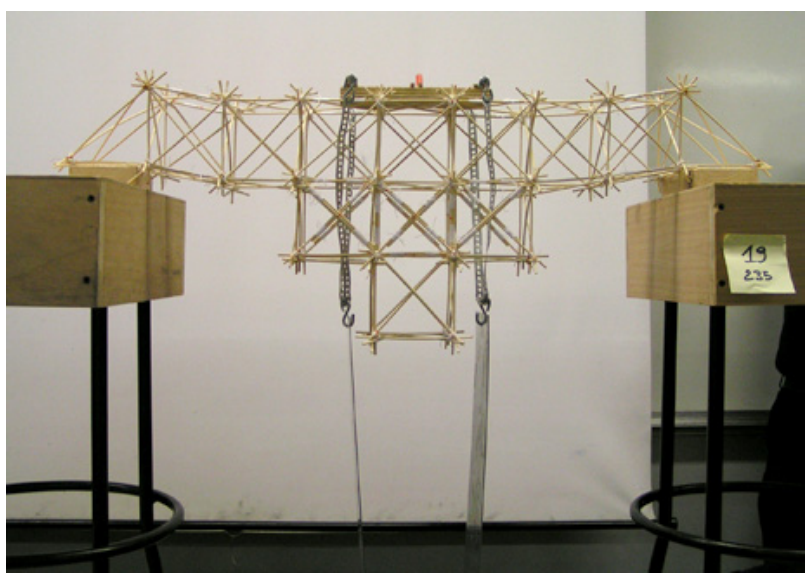

Fig. 12 Bridges testing in the classroom.

\section{Conclusions}

An assessment of the overall experience of the studio is not easy, in terms of impacts on the training of students. The judgment must be limited to the short segment of initial training, in which the building workshops are confined. The method adopted contributes to the perception of the great complexity of the process of architectural design, acquisition of an attitude of paying attention to the design choices and to the detail in the development of creativity. Creativity must be understood not as the supremacy of the free imagination, but as the ability to imagine solutions within a defined field of existence, starting 
with the recognition of the nature of the design problem, without eliminating the margin of uncertainty, though at least reducing it, and without compressing the formal intentions of the designer.

The teaching method seems to be quite efficient with regard to the particular teaching situation: students in the early years of the degree course in architecture, who have basic training and very different personal attitudes, great "design ignorance" but equally great curiosity and potential of creative imagination, being still "virgin" from the point of view of architecture languages and styles.

The key to the method lies in the strategy to begin designing tackling simple problems in a comprehensive way, rather than trying to grossly simplify complex problems, with the risks of "imitating" architecture without understanding it and confusing representation with reality.

\section{Acknowledgments}

The teaching experience described here was developed within the Studio Courses of Construction of Architecture, held at the Department of Sciences for Architecture, University of Genoa, in the second year of the degree course, by the teachers Fausto Novi, Adriano Magliocco and Andrea Giachetta, with the help of Giacomo Cassinelli, Tania Costa, Katia Perini and Chiara Piccardo.

\section{References}

[1] Ockman, J. 2012. Architecture School: Three Centuries of Educating Architects in North America. Cambridge: MIT Press.

[2] Wood, A. 2006. "Demystifying Construction." Architectural Engineering and Design Management 2: 5-18.

[3] Raiteri, R. 2014. Progettare Progettisti. Un Paradigma della Formazione Contemporanea. Macerata: Quodlibet Studio. (in Italian)

[4] Kratzner, D. 1997. "The Practical as Instrument for Technological Imagination." Journal of Architectural Education 51: 32-6.

[5] Lawson, B. 2005. How Designers Think: The Design Process Demystified. Burlington: Elsevier.

[6] Frampton, K. 2001. "Technoscience and Environmental Culture: A Provisional Critique." Journal of Architectural Education 54: 123-9.

[7] Wetzel, C. 2012. "Integrating Structures and Design in the First-Year Studio." Journal of Architectural Education 66: 107-14.

[8] Novi, F., and Piccardo, C. 2015. "Technology as a Key for Design Imagination, an Italian Experience with Beginner Architecture Students." Architectural Engineering and Design Management 11: 185-97. 